\title{
SIMULATION OF A FAULT RUPTURE MECHANISM BY A TWO-DIMENSIONAL FINITE ELEMENT METHOD
}

\author{
Kenzo TokI* and Fusanori MIURA** \\ *Disaster Prevention Research Institute, Kyoto University, Kyoto, Japan \\ **Faculty of Engineering, Yamaguchi University, Yamaguchi, Japan
}

(Received April 22, 1985 ; Revised October 7, 1985)

In the dislocation theory, focal parameters such as the fault area, dislocation, source-time function, rupture velocity, rise time, etc. are assumed in advance of calculation. But, in actual situations, these parameters are the results of fractures on the fault plane. To produce this physical condition in the analysis of the focal rupture mechanism, the process of successive rupture must be analyzed as a phenomenon of fracture caused by external forces on the fault plane. The finite element method is a promising tool for this type of analysis.

In this report, only the stress drop and yielding stress values of the fault being considered are assumed. Parameters that are assumed to be controlling parameters in the dislocation theory are obtained by results of numerical computations using the proposed method. In our analysis, rupture begins at some point on the fault where mobilized shear stress reaches the yielding stress value, then the rupture is transmitted successively along the fault. The driving force of successive rupture is the released strain energy produced by the tectonic force applied laterally on the far field of the crust. The focal parameters obtained from simulations compare well with the empirical relationships of focal parameters determined from past seismic data. The analysis is two dimensional, with a thrust type fault plane being treated. Emphasis is on the approach rather than on results developed during application.

\section{Introduction}

In the past two decades, the investigation of the fault rupture mechanism has advanced remarkably, and a number of approaches for analyzing this mechanism have been proposed. Although most can describe the general features of recorded seismic waves, the time and spatial distributions of dislocation on a fault plane are assumed in calculations of the displacement field based on the elastic wave transmission theory in a half or infinite space. Therefore, dislocation of the fault plane is specified in advance as the boundary condition from which is solved the wave equation that governs the displacement field of the space. In an actual earthquake, however, dislocation is the result of rupture on the fault that is caused by the tectonic force; consequently, the development of rupture is 
a time function which represents its development; this is the source-time function. In the dislocation theory, this source-time function is assumed to express the development of ruptures. Moreover, the size of the fault to be fractured also is assumed, and all controlling parameters are specified on the fault plane prior to analysis.

In an actual fault plane, rupture begins at some point on the fault plane, then is transmitted, which in turn yields successive ruptures in adjacent regions. Therefore, the area of the ruptured zone is governed by the stress field and the strength of the fault plane. The source energy that develops ruptures is generated from the fault plane itself, or an adjacent area, and the energy released is radiated to the nearby field of the fault. This energy basically is stored as strain energy, due to the tectonic force. Therefore, dislocation on the fault plane is not a cause, but a result, of rupture. To describe the process of fracture on a fault plane, the finite element method provides a promising approach because it can analyze strongly nonlinear phenomena such as fracture, and both dynamic and static processes are used in the analyses.

The finite element method now is widely applied to geological and geophysical problems; but, some difficulties in analyzing fault movement remain. This is because when a fault develops in the crust, contiguous portions of the crust are displaced dynamically relative to each other across a discontinuous plane, and strain energy is transformed into kinetic energy that is transmitted by seismic waves. The classical finite element technique, however, cannot analyze such a complex phenomenon; therefore, a sophisticated technique with which to analyze fault movement by the finite element method must be established.

As the first step in applying the finite element method to the analysis of fault rupture, the problem is analyzed statically. JUNGLES and FRAZIER (1973) introduced a discontinuity in the finite element formulation, which is based on twodimensional plane strain analysis. First, they examined the accuracy of a twodimensional approximation by comparing it with three-dimensional analytical results. They then applied the method to an analysis of zero frequency seismic data represented by the permanent displacement data recorded in the 1971 San Fernando earthquake. Melosh and RAEFSKY (1981) proposed a 'split node technique' for introducing fault displacements into finite element numerical computations. They used their technique to study anelastic relaxation of stress in the earth after an earthquake, and it proved very satisfactory.

McCown et al. (1977) also proposed a two-dimensional finite element model that considers discontinuity by arranging a 'double row of nodes' along a fault. They made an inversion analysis using the dislocation data from the 1971 San Fernando earthquake and obtained estimates of the dislocation and stress drops along the actual fault surface using the static approach. Using these calculated stresses in a dynamic model of the earthquake, they computed low frequency accelerograms for the Pacoima Dam site and showed the most suitable fault model. ARCHULETA and FRAZIER (1978) presented a method for simulating earthquakes 
that is based on dynamic, propagating stress drops over a finite plane in a threedimensional semi-infinite medium. They first verified the method by comparing their numerical results with Kostrov's (1964) solution. They then adopted the method to simulate two strike-slip earthquakes. However, they used a symmetry model in which the fault plane is vertical. Therefore, their method cannot be applied directly to a dipping fault, and the rupture velocity must be specified a priori because a rupture does not propagate spontaneously in the dynamic analyses proposed above.

We (Toki et al., 1981, 1983) have developed a computer program in which to investigate nonlinear soil-structure interaction during strong earthquake ground motion that uses a joint element to represent a contact surface between the soil and a structure, such as a building or bridge. This approach has been so successful in representing the sliding and separation between soil and a structure such as a building that it has been used to analyze the sliding of an actual slope subjected to strong ground shaking (Toki et al., 1985).

In another application, we have used the same method to analyze the rupture mechanism of a fault because rupture is a type of sliding of rock blocks that come in contact with each other. In this approach, the source of the force that ruptures the contact surface of a fault is the strain energy released by the stress drop. In advance of the analysis of the dynamic process, the tectonic force is applied at both lateral ends of the finite element model to increase the stress field in the crustal rock. When the shear stress in an element on the fault plane reaches the yielding shear stress value, the strain energy of the element is released and is radiated to the neighboring region. It is the strain energy of those elements being increased by the transmitted energy which triggers the rupture of the respective element. Thus, rupture is considered to be successive on the fault plane. Therefore, our method does not demand assumptions about such parameters as fault dimensions, source-time function, rupture velocity, etc.; only the yielding strength and the stress drop, in addition of the physical properties of the crust are necessary to make an analysis.

Mikumo and MiYatake (1978) and MiYatake (1980 a, b) treated rupture propagation using a quasi-three dimensional and a three dimensional finite difference method, respectively. They investigated a crack propagation pattern on a fault plane and characteristics of generated seismic waves using barrier models. Their methods were similar to the one we have used. Ruptures propagate spontaneously under given initial stresses and yield strength of the crust in both methods. This distribution of initial stress in their methods is, however, assumed independently of the material property and structure of the crust. On the other hand, in our method, initial stress is physically determined by static analysis, reflecting the material property and structure of the crust and tectonic force. Moreover, by our method material nonlinearity of the crust can easily be taken into consideration in the analysis. 
(a)

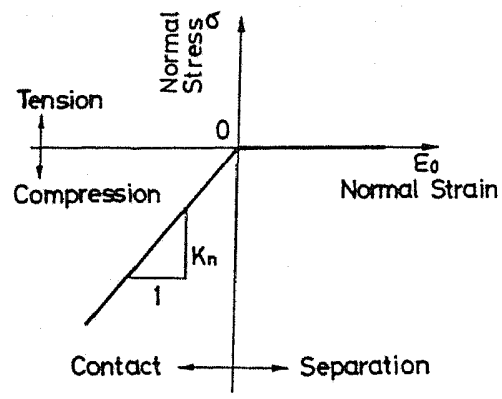

(b)

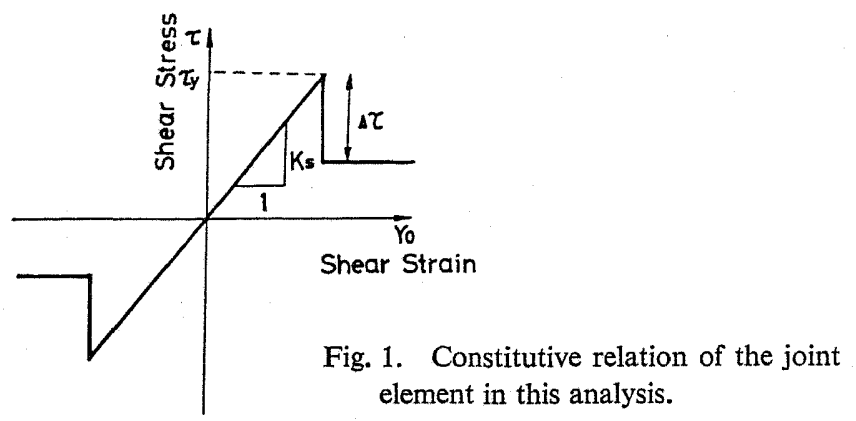

\section{Method of Analysis}

\subsection{Modeling the fault}

The fault plane is modeled by a joint element which is composed of two solid elements coming in contact and which has three different modes of deformation; motion that is parallel, perpendicular, and rotational to each subelement. When tensile force is induced, the joint element separates and no force is transmitted through the joint wall. Sliding takes place if the mobilized shear stress reaches the yielding shear stress, $\tau_{y}$, which is determined in terms of the cohesion $C$, the normal stress $\sigma$ and the internal friction angle $\phi$, of the contact surface as shown by

$$
\tau_{\mathrm{y}}=C+\sigma \tan \phi .
$$

The condition for local rupture on the fault plane is therefore represented by parameters related to the strength of the respective portion of the fault. The stiffness, $k_{s}$, of the linear region of (b) in Fig. 1 was chosen so that the stiffness matrix is 3 to 5 times that of the solid element that expresses the rock material. Although the stiffness, $k_{n}$, for the compression side in Fig. 1(a) should be infinite, the same value as that used for the shearing direction was chosen because of the difficulty of making numerical computations (ToKI and MrURA, 1983).

When rupture is initiated, a dynamic stress drop occurs as shown in Fig. 1(b); thus, the extent of the stress drop must be given in advance of analysis. The stress 
(a)

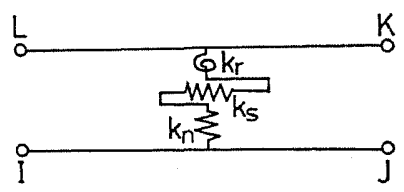

(b)

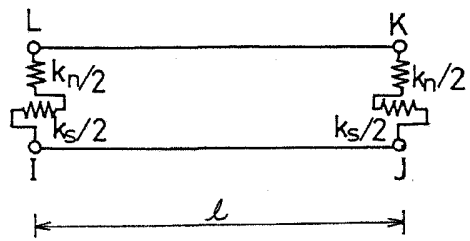

Fig. 2. (a) Schematic representation of the joint element by Goodman. (b) Schematic representation of a modified joint element for this analysis.

value after the stress drop was kept constant (Fig. 1(b)). We also assumed that stress drop takes place within the time step used in our numerical computations; $0.02 \mathrm{~s}$.

In a previous study (ToKI et al., 1983), we used the joint element proposed by Goodman (1976) to represent the fault. This joint element, however, gave a rupture velocity that was faster than the P-wave velocity of the crust, which is not physically acceptable. This joint element is shown schematically in Fig. 2(a). To avoid this problem, we modified the joint element and obtained the physical model shown in Fig. 2(b). In this model, deformation of the nodal pair L, I does not occur at the same time as that of K, $\mathrm{J}$ in Fig. 2(b). Instead, it is induced by deformation of the solid element connected to the joint element. Furthermore, conditions for sliding and separation are tested independently at both ends of the joint element; therefore, the rupture velocity never becomes faster than the elastic wave velocity of the crust. The stiffness matrix of this modified joint element $[K]$ is given as

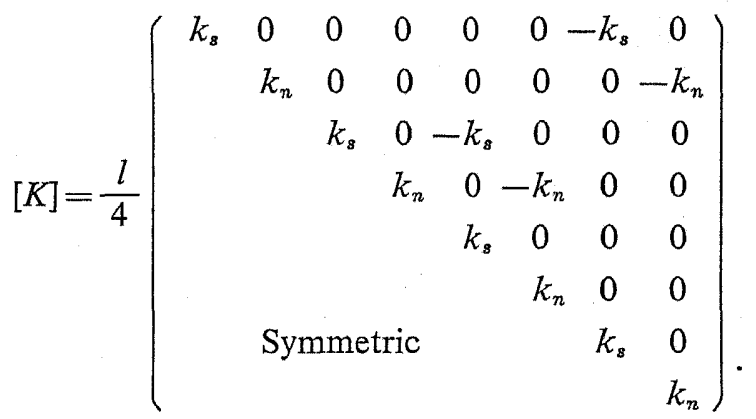

\subsection{Initial stress distribution}

Stress distribution due to gravity was determined by the following equation in order to obtain the equivalent nodal forces $\{f\}$ :

$$
\{f\}=\int_{\mathrm{V}}[N]^{\mathrm{T}}\{p\} \mathrm{d} v
$$




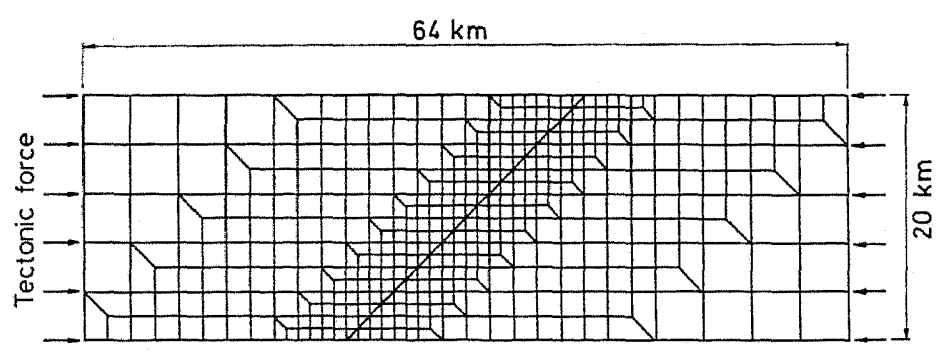

Fig. 3. Finite element mesh for the calculation of the initial stress distribution.

in which $[N]$ is the matrix of the shape function, $\{p\}=\{0-\rho g\}^{\mathrm{T}}, \rho$ the density and $g$ the acceleration of gravity. The stress field was then calculated by following the ordinary procedure. At this stage, the shear stress on all the joint elements that compose the fault plane was reduced to zero because the shear stress on the fault plane due to gravity had been considered to be released in past earthquakes.

Tectonic force then was applied in the lateral direction at both lateral ends of the model shown in Fig. 3 to determine the initial stress distribution. The force applied was uniform at both ends and was increased gradually until the mobilized shear stress of a joint element reached the yielding strength of that element. At this stage, the stress field was "frozen" and transferred to the model for dynamic analysis.

\subsection{Dynamic analysis}

The model for dynamic analysis (Fig. 4) has a finite element mesh that is the equal-size of one square kilometer. Because in this state, the shear stress on an element on the fault coincides with the rupture strength of that element, rupture is immediate and the strain energy of the element is released. This released energy is transformed into kinetic energy and transmitted by elastic waves to the neighboring region, which in turn redistributes the stress field in the crust.

The procedure of dynamic analysis has been described in our previous papers (ToKI et al., 1981, 1983, 1985), but some procedures have been modified slightly for the analysis of rupture on a fault plane. Dynamic analysis is basically a nonlinear analysis because sliding and separation phenomena are concerned. The equation of motion, therefore, must be solved in the time domain; that is, a direct integration of the equation of motion in the time domain must be made. The equation of motion at time step $n$ is written

$$
[M]\{\ddot{u}\}_{n}+[C]\{\dot{u}\}_{n}+[K]\left\{u_{n}=\{g(t, s)\}\right.
$$

in which $[M],[C]$, and $[K]$ are the respective mass, damping and stiffness matrices of the system; $\{g(t, s)\}$ is the external force vector calculated from the dynamic stress drop $\Delta \tau$; and $t$ and $s$ stand for time and nodal pairs where sliding takes place. At the first time step $(t=0), g(0, s)$ is given as 


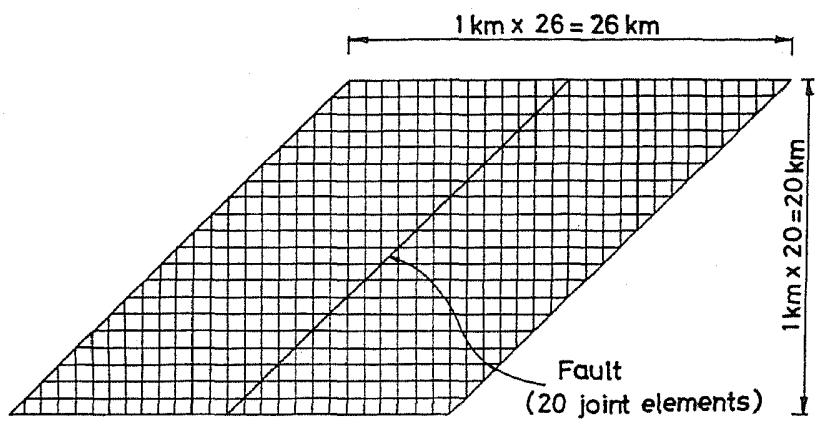

Fig. 4. Finite element mesh for the dynamic analysis of the fault-rupture process.

$$
g(0, s)=\frac{l \cdot \Delta \tau}{2}
$$

and it is applied to the nodal pairs where sliding is taking place. The direction of the nodal forces must coincide with the direction of the initial shear stress. $l$ is the length of the joint element. The shear stress of the joint element, $\tau$, is kept constant when the joint element is sliding and its magnitude is being given as $\tau=\tau_{y}-\Delta \tau$, in which $\tau_{y}$ is the yield shear stress. The nodal force given by Eq. (5) produces stress redistribution and increases the shear stress on the neighboring joint elements.

When the shear stress of the next nodal pair reaches the yield shear stress, sliding takes place at that pair. Let the time be $t_{j}, g\left(t_{j}, s\right)$, as obtained from Eq. (5) and applied to nodal points of the element at the stated time. $t_{j}$ is obtained by solving Eq. (4); it is not specified in advance as in other studies. In this manner rupture is successive in each element.

The rupture velocity $V_{r}\left(t_{j}\right)$ at $t=t_{j}$ is calculated as follows:

$$
V_{r}\left(t_{j}\right)=\Delta l / \Delta T
$$

in which $\Delta l$ is the distance between two neighboring nodal pairs which slid successively at $t_{j}$ and before $t_{j} . \Delta T$ is the interval for the two successive slips at $t_{j}$ and before $t_{j}$.

NEWMARK's (1959) $\beta$ method ( $\beta=1 / 4$ ) is used in this time-marching algorithm. The load transfer method is employed to solve the nonlinear equation of motion, in which the stiffness matrix is kept constant throughout the analysis. By virtue of the constant stiffness, the CPU time is greatly reduced in comparison to such other schemes for the numerical integration of a nonlinear equation, such as the Newton-Raphson method.

In the finite element analysis of seismic behavior of the ground, the region is truncated and the reflection of seismic waves at the boundaries eventually is induced. To avoid this, we introduced a viscous boundary (LYSMER and KUHLEMEYER, 1969). Although the reflected wave was not completely eliminated, we ascertained that the reflected wave component was not significant when com- 


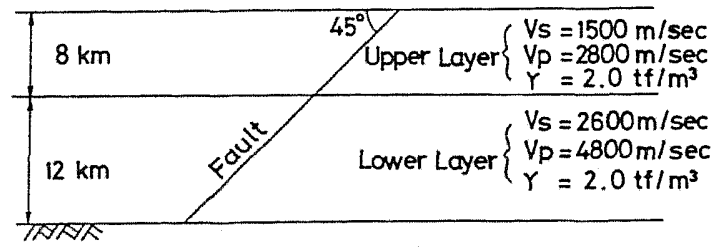

Fig. 5. The model fault analyzed.

Table 1. Model parameters and cases analyzed.

\begin{tabular}{cccccccc}
\hline Crust & $\begin{array}{c}\text { Density } \\
\left(\mathrm{tf} / \mathrm{m}^{3}\right)\end{array}$ & $\begin{array}{c}V_{\mathrm{S}} \\
(\mathrm{m} / \mathrm{s})\end{array}$ & $\begin{array}{c}V_{\mathrm{P}} \\
(\mathrm{m} / \mathrm{s})\end{array}$ & Case & $\begin{array}{c}\text { Cohe- } \\
\text { sion } \\
(\text { bar })\end{array}$ & $\begin{array}{c}\text { Friction } \\
\text { angle } \\
(\mathrm{deg})\end{array}$ & $\begin{array}{c}\text { Stress } \\
\text { drop } \\
(\text { bar) }\end{array}$ \\
\hline Upper layer & 2.0 & 1,500 & 2,800 & 1 & 35 & 0 & 30 \\
Lower layer & 2.0 & 2,600 & 4,800 & 2 & 70 & 0 & 30 \\
& & & & 3 & 70 & 0 & 45 \\
& & & 4 & 70 & 0 & 60 \\
\hline
\end{tabular}

pared with the intensity of the directly transmitted wave.

\section{Model Fault Analyzed}

\subsection{Analyzed cases}

The joint elements were arranged along a potential fault plane that was assumed to have been fractured in the past, but this does not necessarily indicate sliding of the whole region under the present tectonic force. The dip angle was assumed to be $45^{\circ}$ (Fig. 3). The mesh size is not the same throughout the model; a fine mesh size in the vicinity of the fault and a large mesh size in the distant region were used for static analysis but sizes were the same throughout the model with dynamic analysis (Fig. 4). A two-dimensional isoparametric element was used for the solid elements that represented the rock material.

The model fault analyzed in our study is shown in Fig. 5. The thickness of the first layer is $8 \mathrm{~km}$ and the second $12 \mathrm{~km}$. The density, along with P- and Swave velocities of each layer are listed in Table 1 . The value of $Q$ was measured as 200 at $1 \mathrm{~Hz}$ and 22.5 at $0.1 \mathrm{~Hz}$, assuming Rayleigh damping. The finite element mesh shown in Fig. 4 was determined from the model fault of Fig. 5. The number of elements is 588 and the degree of freedom is 1,176 . In finite element analysis, it is desirable to use 6 to 8 elements to represent a wave length (KUHLEMEYER and LYSMER, 1973). At least two elements are necessary, which means that the size of the element governs the upper limit of the frequency components to be analyzed. In our analysis, the mesh size is $1 \mathrm{~km}$; consequently, the shortest wavelength becomes $2 \mathrm{~km}$. Because the S-wave velocity is $1.5 \mathrm{~km} / \mathrm{s}$, the highest possible frequency component is $0.75 \mathrm{~Hz}$.

Four different situations, Cases 1 to 4 , are set up as shown in Table 1. Dy- 
namic stress drops in Cases 1 and 2 are 30 bars, in Case 3, 45 bars and in Case 4, 60 bars. The value of cohesion, i.e. the shear strength, of the joint element was 35 bars for Case 1 and 70 bars for the others. A zero value was assigned to the friction angle of the joint elements for the first $16 \mathrm{~km}$ of depth and $30^{\circ}$ for the last $4 \mathrm{~km}$, which represents a solid region that had not ruptured in the past. Therefore, the potential fault length is $22.6 \mathrm{~km}$. Cases 1 and 2 were prepared to compare the differences in the yield stresses. The effect of the stress drop is seen in the comparisons of the behavior of the fault for Cases 2, 3, and 4.

\subsection{Initial stress distribution}

The shear stress distribution produced by tectonic force is shown in Fig. 6, in which the yield stress is represented by a broken line. At this stage, the mobilized shear stress on the first element of the second layer has reached the yield stress, as shown in the figure. Therefore, a rupture will be triggered at this point and transmitted to the lower and upper regions of the crust. The stress level in the second layer is greater than that in the first layer, a reflection of the stiffness of the layers. Because the initial stress distribution is governed only by the stiffness of the layers, distributions for Cases 2,3 , and 4 are the same and distribution for Case 1 is one half of the others because the yielding stress is one half of their value.

\subsection{Development of rupture}

The development of rupture in Cases 1 to 4 is shown in Figs. 7(a) to (d). In

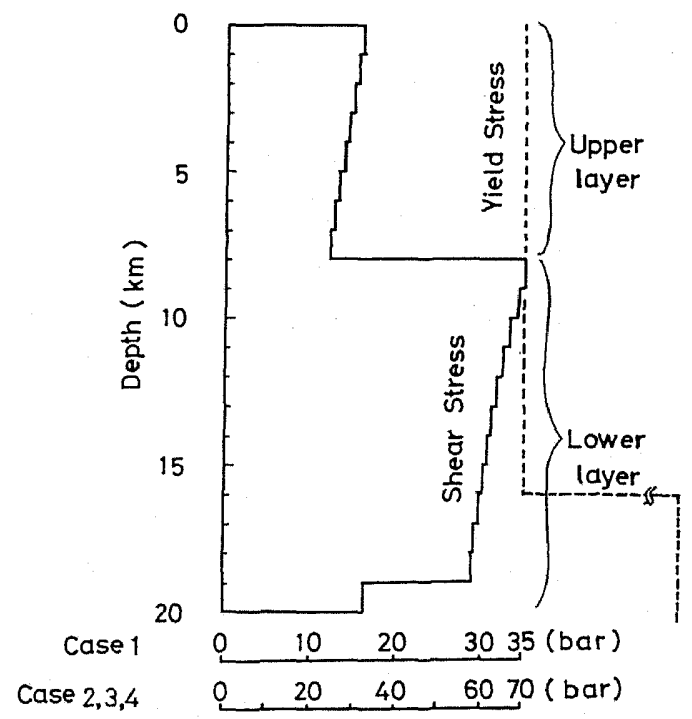

Fig. 6. Initial shear stress distribution along the fault plane for Cases 1 to 4 . 


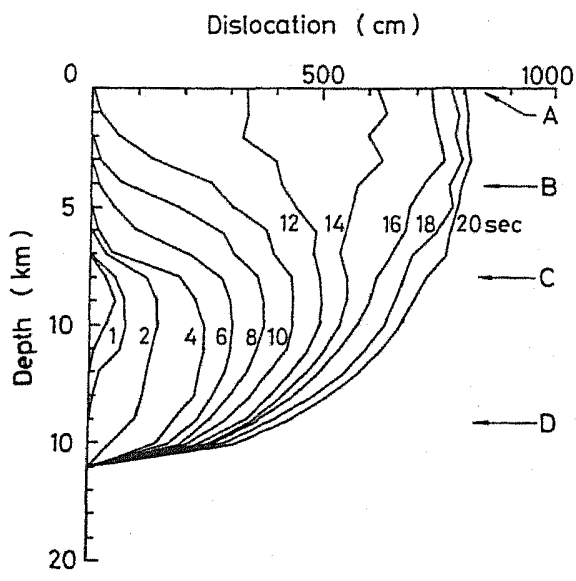

(a)

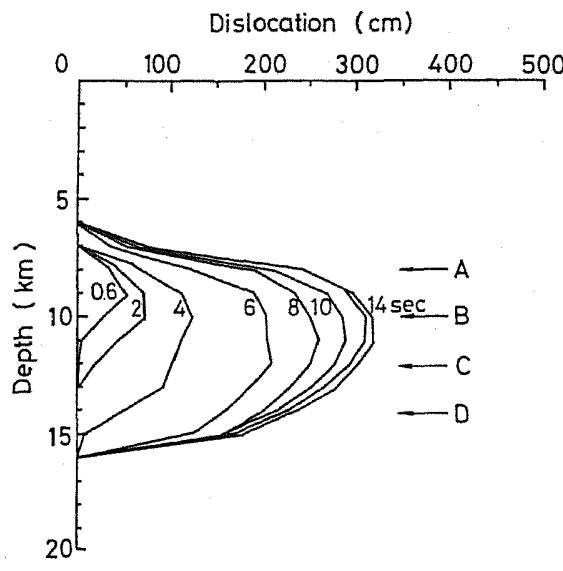

(b)

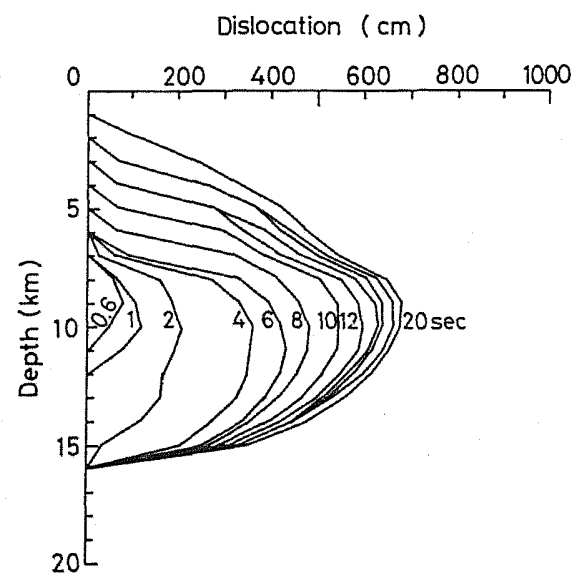

(c)

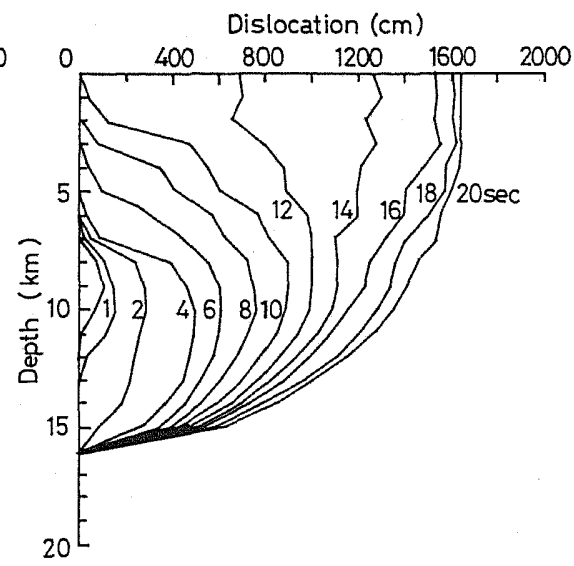

(d)

Fig. 7. Development of the fault rupture with time. (a) Case 1, (b) Case 2, (c) Case 3, (d) Case 4.

this figure the abscissa shows the magnitude of dislocation and the ordinate the depth for the ground surface. The parameter in these figures indicates the time elapsed after rupture has begun. In all cases, rupture began at the lower side of the interface between the first and second layers then developed towards the lower region of the second layer where the difference between the mobilized and yield stress is smaller than that of the first layer. After this rupture reached the bottom of the second layer, rupture of the first layer began. In Case 2, the last $4 \mathrm{~km}$ of the second layer was assumed never to have ruptured in the past; therefore, its yielding stress is very high (1,400 bars), and the rupture stopped $4 \mathrm{~s}$ after it initially began. After a 2-s stop at a depth of $16 \mathrm{~km}$, rupture in the first layer began again, stopping $6 \mathrm{~km}$ from the surface (Fig. 7(b)). As shown in (a) and (b) of Fig. 7, 
(a)

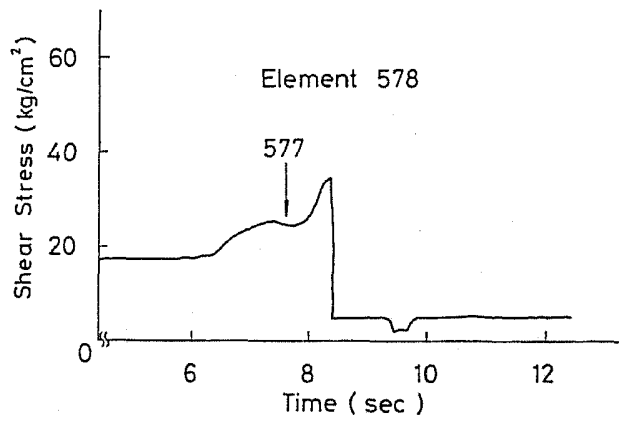

(b)

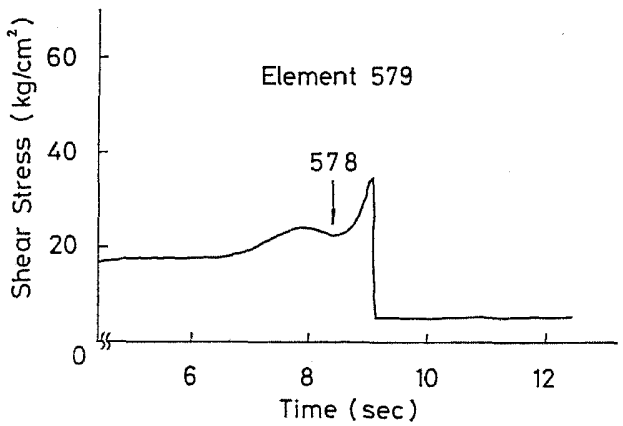

(c)

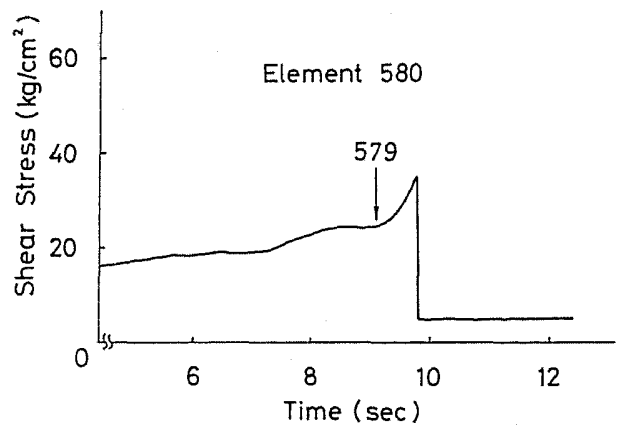

Fig. 8. Time history of shear stress (Case 1). (a) Element 578, (b) Element 579, (c) Element 580.

a comparison of the results for Cases 1 and 2 demonstrates the effect of the yielding stress on the fault plane. In Case 1, in which the yielding stress is half that of Case 2 , rupture reached the surface of the ground and dislocation was greatest there. The rupture stopped after $14 \mathrm{~s}$ in Case 2, but it continued beyond $20 \mathrm{~s}$ in Case 1 . Comparing Case 1 with Case 4, in which the ratio of the dynamic stress drop to the yielding stress is the same, we find that the development of dislocation was similar, but the magnitude of dislocation in Case 4 was as much as twice that found in Case 1 .

The yielding stress is the same in Cases 2 to 4 but the dynamic stress drops differ; 30,45 , and 60 bars. Comparing these three cases, we find that the magnitude of dislocation depends on the stress drop, but is not linearly proportional to it; the difference in dislocation is greater than that in the stress drop. There- 


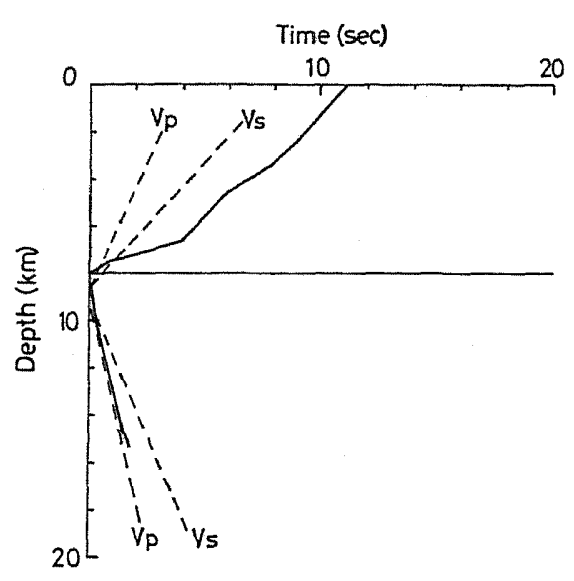

(a)

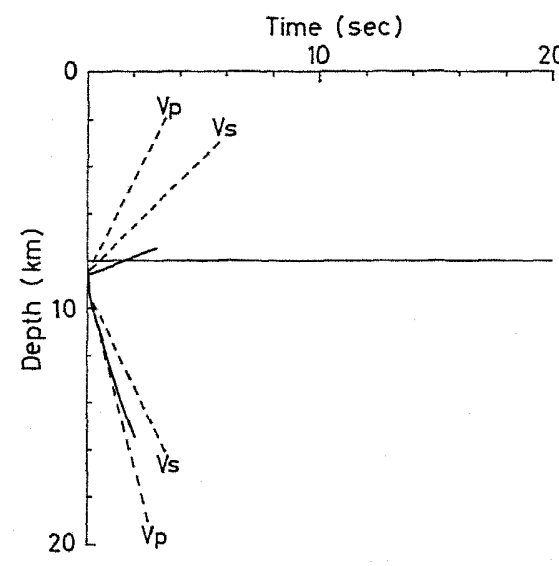

(b)

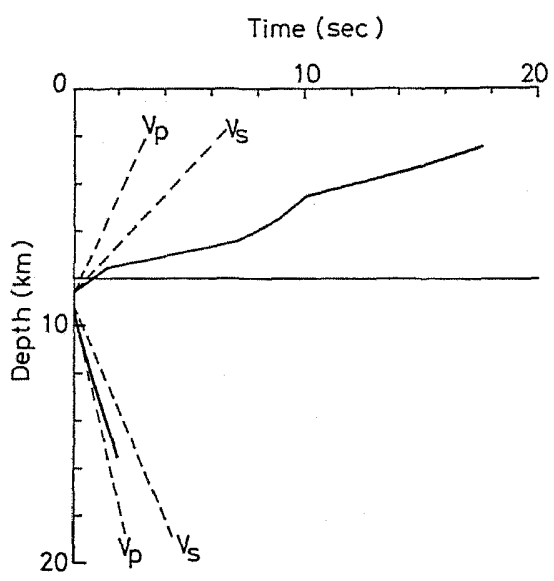

(c)

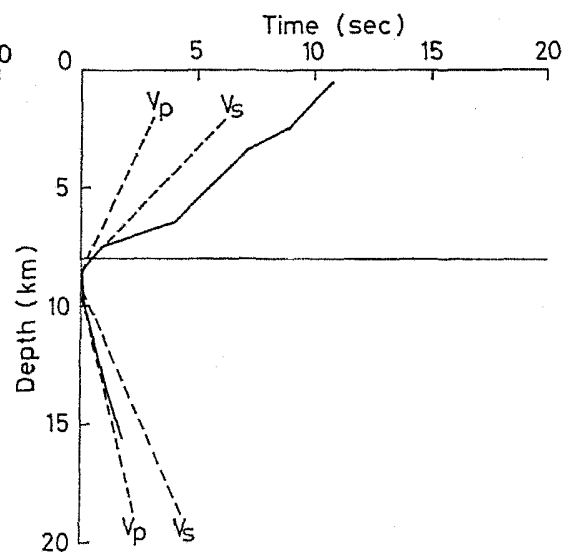

(d)

Fig. 9. Trace of the wave front of simulation (solid line) and of theoretical $\mathrm{P}$ and $\mathrm{S}$ waves (dashed lines). (a) Case 1, (b) Case 2, (c) Case 3, (d) Case 4.

fore we have concluded that the magnitude of dislocation depends both on the stress drop and on the yielding stress and that it is proportional to the stress drop, if the ratio of the stress drop to the yielding stress is the same.

Time histories of the shear stress on three joint elements beneath the surface in Case 1 are shown in Fig. 8; arrows indicate the time when the next joint element concerned slid. The element number becomes smaller with increasing depth, the number 580 corresponding to the surface. These figures indicate that the shear stress on every element increases sharply in proportion to the yielding stress value immediately after the previous element is fractured. This is the same in Cases 2, 3, and 4. As shown, our method describes the process of the redistribution of stress in adjacent regions of the fault, and this indicates the usefulness of 

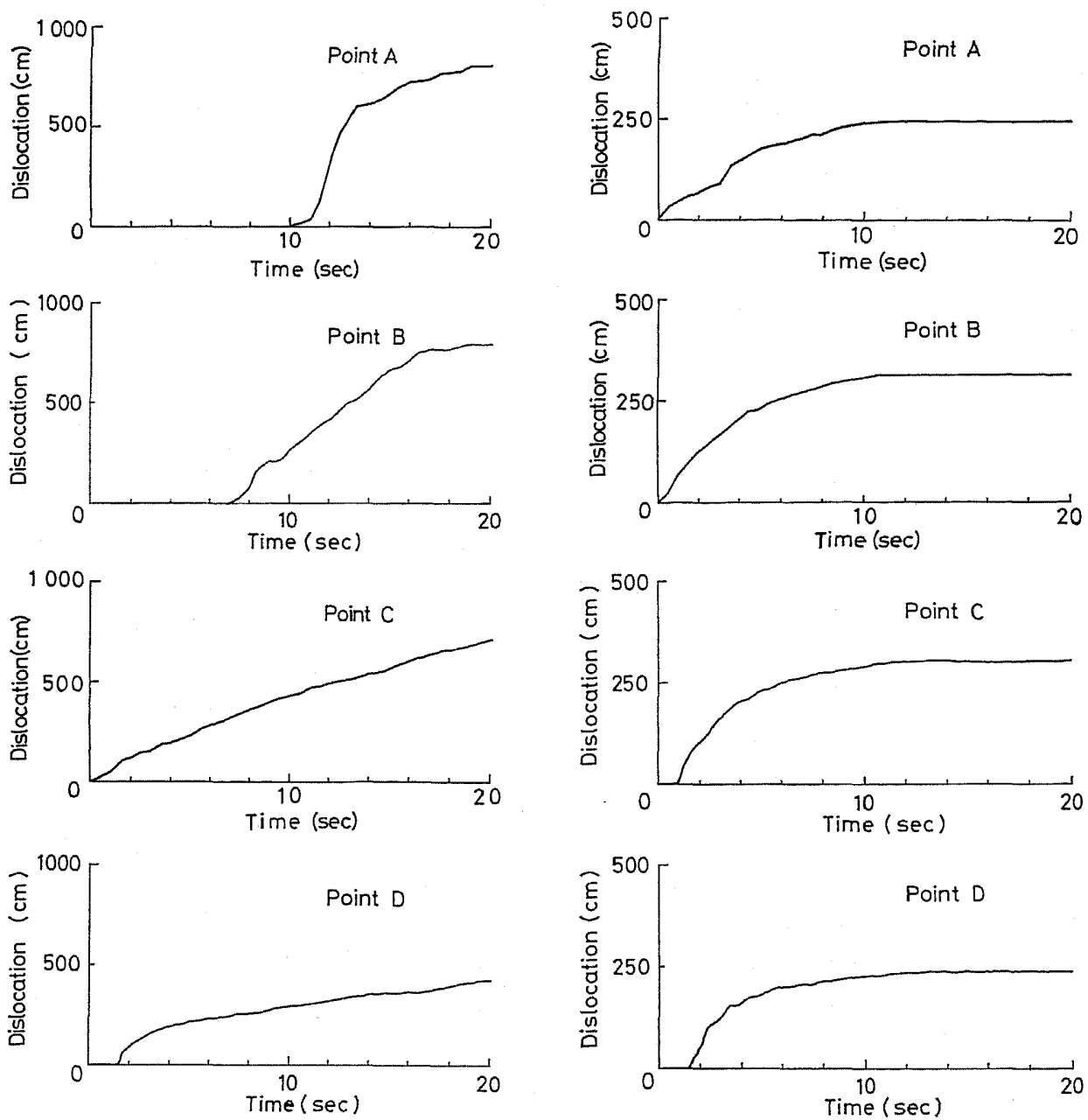

Fig. 10

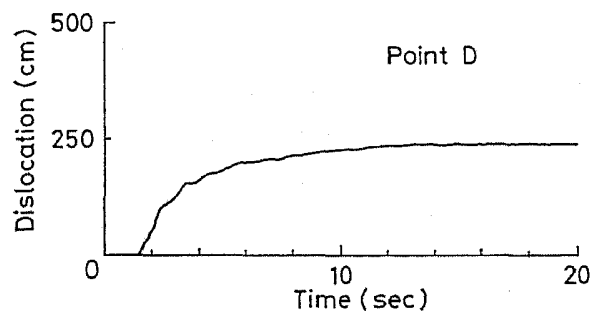

Fig. 11

Fig. 10. Source-time function in Case 1.

Fig. 11. Source-time function in Case 2.

this method for analysis of the barrier model treated later.

Figure 9 represents the development of rupture with time, (a) to (d) corresponding to Cases 1 to 4 . The vertical axis shows the depth from the surface and the horizontal one time. The solid line shows the rupture front and broken lines indicate the wave front of the $P$ and $S$ waves. These sub-figures show that the rupture velocity in the second layer comes between the $\mathrm{P}$ - and S-wave velocity and that the velocity in the first layer is less than the S-wave velocity. The development of rupture in Case 4 is very similar to that in Case 1 . These two cases have the same ratio of dynamic stress drop to yielding stress, as stated previously, and 


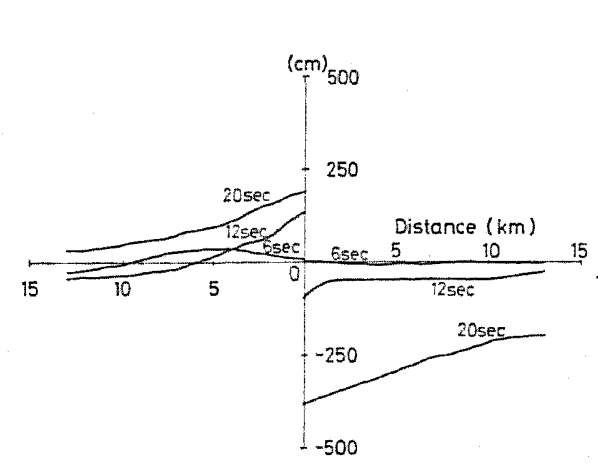

(a)

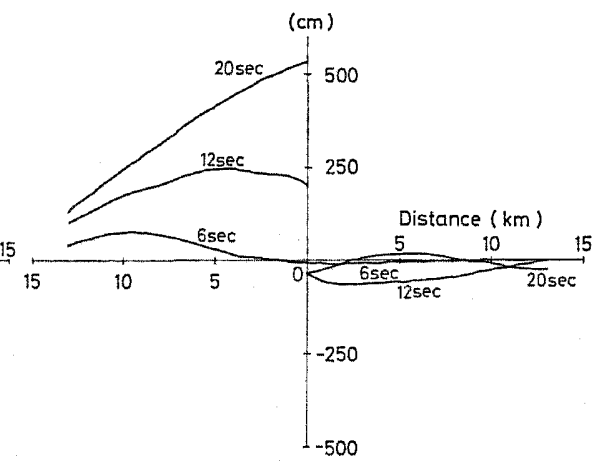

(b)

Fig. 12. Attenuation of displacement in Case 1. (a) Horizontal component, (b) vertical component.

the development of rupture is almost the same although the magnitude of dislocation differs. These results indicate that the rupture velocity and the development of dislocation can be discussed in terms of the ratio of the stress drop to the yielding stress drop. MiYATAKe $(1980 \mathrm{a}, \mathrm{b})$ also showed that the rupture velocity depends on both initial stress and yielding stress.

The development of dislocation for Cases 1 and 2, shown in Figs. 10 and 11, corresponds to the source-time function in the dislocation theory. The capital letters $A$ to $D$ in these figures stand for the points shown on the ordinate of Figs. 7(a) and (b). In the dislocation theory, the source-time function usually is represented by the linear function of time and is assumed to be the same throughout the fault plane. As seen here, however, the source-time function is a more complicated function of time, and the shape differs depending on the location on the fault. This is also pointed out by ARCHULETA, and FrazIER (1978), Mikumo and Mryatake (1978), Mryatake (1980 a, b) and others.

The distributions of displacement along the ground surface are shown in Fig. 12 for Case 1, in which rupture has reached the ground surface; (a) is the horizontal and (b) the vertical component. The parameter is time elapsed after rupture starts. Displacement of the lower block of the fault is greater than that of the upper block in the horizontal direction, the converse being true in the vertical direction. The reason for this may be that vertical displacement is dominant in the upper block due to the thrust force and that the horizontal component of the lower block is the result of the extension of the lower block due to the decrease in resistance caused by the lifting up of the upper block.

Figure 13 shows the deformation at $20 \mathrm{~s}$ in Case 1 . The time histories of acceleration, velocity and displacement for the horizontal and vertical components are shown in Figs. 14 and 15; (a) the upper block and (b) the lower block. The arrows in these figures show the moment when the previous element slid. These figures also show the difference in behavior of the upper and lower blocks and 


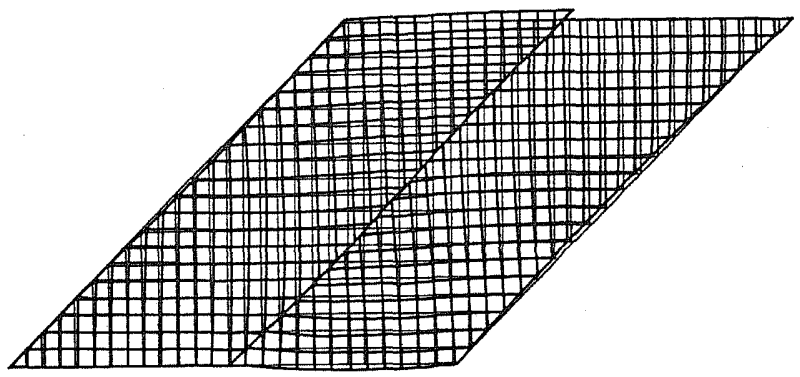

Fig. 13. Deformation at $20 \mathrm{~s}$ in Case 1.
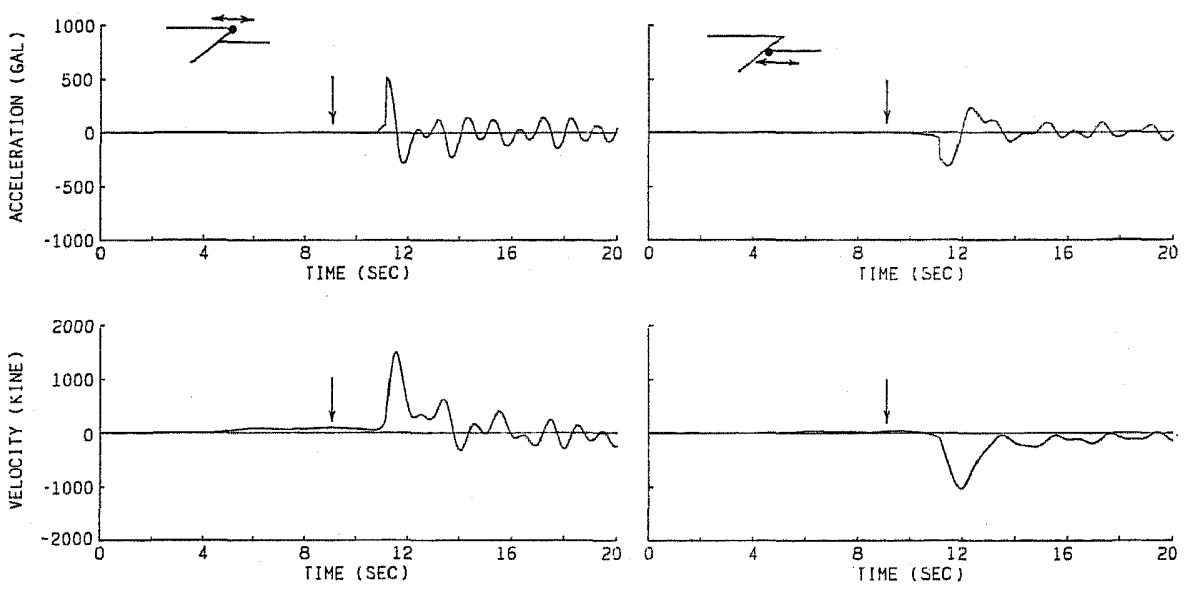

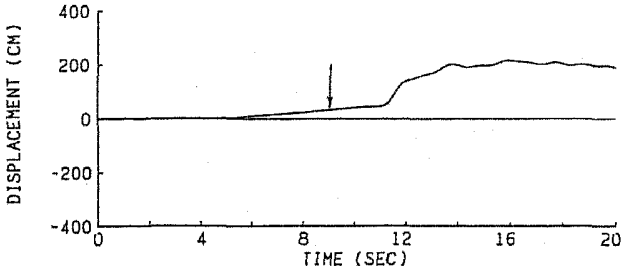

(a)

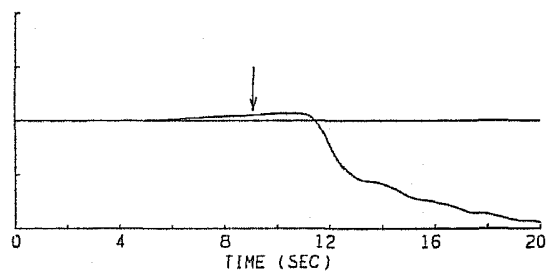

(b)

Fig. 14. Deformation curves for the horizontal component in Case 1. (a) Upper block, (b) lower block.

that our conclusion about peak acceleration also is valid for velocity and displacement.

The attenuation characteristics of peak acceleration for the four cases are compared in Fig. 16, the left side of the figures being the upper block and the right side the lower block of the fault. For both the horizontal and vertical components acceleration of the upper block of the fault in all cases is greater than that of the lower block. Similar situations have been observed in the deforma- 

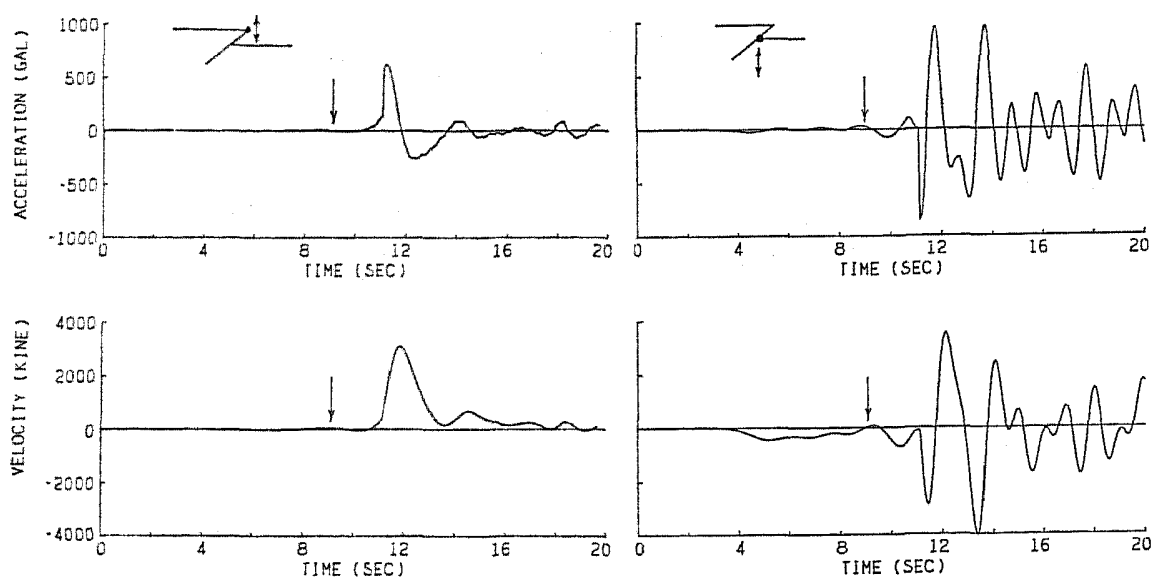

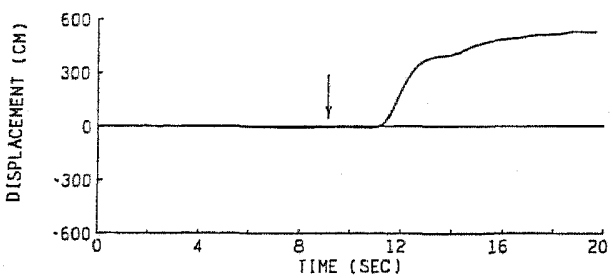

(a)

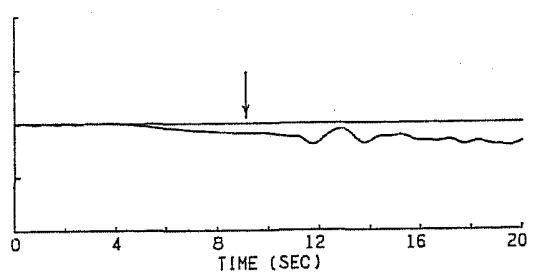

(b)

Fig. 15. Deformation curves for the vertical component in Case 1. (a) Upper block, (b) lower block.

tion of the ground surface caused by actual earthquakes, damage in the upper ground being reported as greater than that in the lower part of the thrust type fault. An example of the attenuation curves for acceleration and the MMI scale is the 1980 Algeria earthquake (Yoshikawa et al., 1981) is given in Fig. 17. The solid line in this figure was drawn from calculations made with the dislocation model. General characteristics of the attenuation curve are similar to those in Fig. 16.

\subsection{Comparisons with theoretical results}

Average global stress drop, $\Delta \approx$, which is a difference between the initial stress and the residual (final) stress, is written in terms of Lamé's constants $\lambda$ and $\mu$ for the crust material with the dislocation magnitude, $D$, of the fault being considered (KANAMORI, 1978):

$$
\Delta \tau=\frac{8 \mu(\lambda+\mu)}{\lambda+2 \mu} \frac{D}{\pi W} .
$$

As this relation is defined as a fault of infinite length and width $W$, it can be used for a two dimensional analysis. The related values in Cases 1 to 4 therefore, were used in Eq. (7) to obtain the average dislocation on the fault; results are listed in 


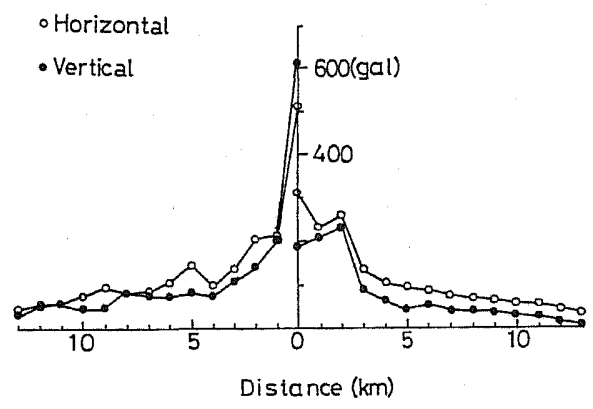

(a)

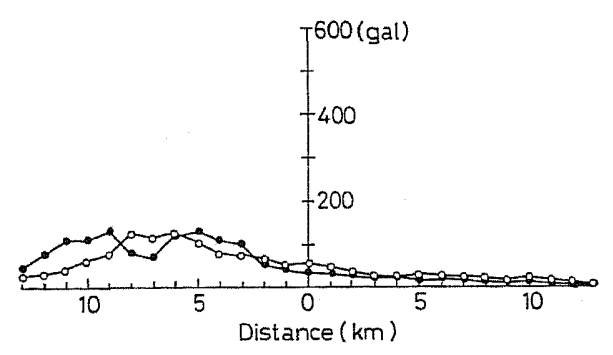

(c)

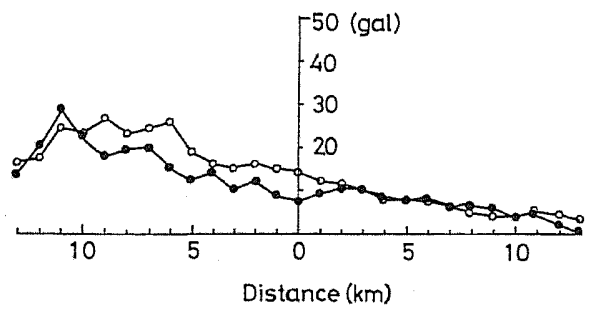

(b)

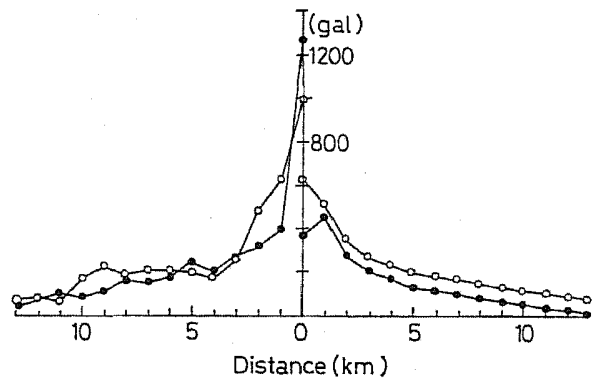

(d)

Fig. 16. Attenuation of peak acceleration. (a) Case 1, (b) Case 2, (c) Case 3, (d) Case 4.

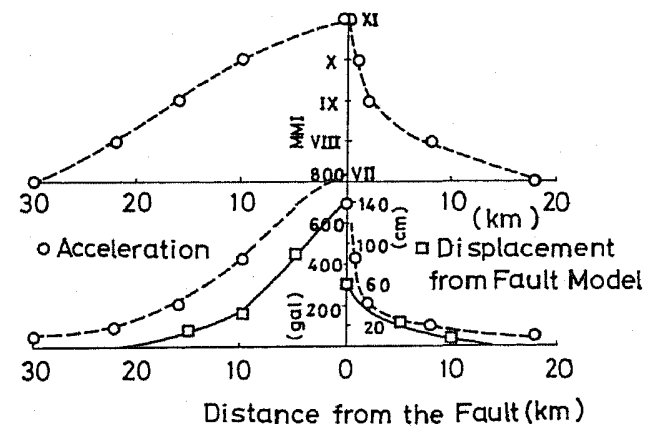

Fig. 17. Attenuation curves for the Algeria earthquake (1980).

Table 2. For stiffness, the intermediate values of the first and second layers were used, i.e., a shear velocity of $2 \mathrm{~km} / \mathrm{s}$ was assumed. To calculate the seismic moment, we used the following relation on the assumption that $L=2 \mathrm{~W}$, the scaling law obtained by KANAMORI and ANDERSON (1975) for shallow earthquakes.

$$
M_{0}=\mu \times D \times S . \quad(S=L \times W)
$$


Table 2. Comparison of values obtained from formula and F.E.M.

\begin{tabular}{|c|c|c|c|c|c|c|c|}
\hline \multirow{2}{*}{ Case } & \multirow{2}{*}{$\begin{array}{c}\text { Global } \\
\text { stress } \\
\text { drop } \\
\text { If (bar) }\end{array}$} & \multicolumn{2}{|c|}{ Dislocation (m) } & \multicolumn{2}{|c|}{$\begin{array}{l}\text { Seismic moment } \\
\left(10^{28} \mathrm{dyn} \cdot \mathrm{cm}\right)\end{array}$} & \multicolumn{2}{|c|}{ Magnitude $M_{\mathrm{S}}$} \\
\hline & & Formula & F.E.M. & Formula & F.E.M. & Formula & F.E.M. \\
\hline 1 & 18.0 & 5.96 & 6.03 & 5.50 & 5.58 & 7.49 & 7.49 \\
\hline 2 & 19.8 & 2.11 & 2.02 & 0.82 & 0.78 & 6.94 & 6.92 \\
\hline 3 & 21.3 & 3.18 & 4.06 & 2.29 & 2.92 & 7.23 & 7.30 \\
\hline 4 & 36.0 & 11.92 & 12.15 & 11.03 & 11.20 & 7.69 & 7.69 \\
\hline
\end{tabular}

Further, $M_{s}$ is converted from $M_{0}$ by the following relation given by GELLER (1976) as;

$$
\log M_{0}=1.5 M_{s}+15.51 . \quad\left(6.8<M_{s}<8.2\right)
$$

The dislocation, seismic moment and magnitude of the earthquake, which were obtained from these relations for each case are listed in Table 2. Because the magnitude of dislocation is not uniform throughout the fault plane, the value of dislocation is the average of the final dislocation of each simulation. For Cases 1 and 4, magnitude of dislocation obtained from Eq. (7) are multiplied by 2, because the rupture reaches the ground surface (ODA and HrRASAWA, 1976), with the results being listed in Table 2. A comparison of the results shown in Table 2 shows that there is strong agreement. Comparing the extent of faulting in Figs. 7(a) to (d) in the cases analyzed, we found that rupture reached the ground surface in Cases 1 and 4 as mentioned above; whereas, in Cases 2 and 3 rupture was confined under the surface. When a rupture reaches the surface, the apex of the upper block of the fault rebounds from its original location due to the strain energy released from the near-surface region. Moreover, in this situation the kinetic energy transmitted from the adjacent area is concentrated at the apex of the upper block, which has a wedge shape and this in turn causes a larger dislocation than that for the confined faults analyzed in Cases 2 and 3.

SATo (1979) showed the relationship between focal parameters and earthquake magnitude which are based on the dislocation theory. The magnitude of dislocation, $D_{0}$, and earthquake magnitude, $M$, is given as;

$$
\log D_{0}=0.5 M-1.40 \text {. }
$$

According to this relation, the magnitude of dislocation for an earthquake of magnitude 6.94 is $120 \mathrm{~cm}$, where the value is less than $202 \mathrm{~cm}$ as in Case 2 where the earthquake magnitude was 6.94 (Table 2). Therefore, the difference in dislocation is about $40 \%$ in this case. Considering the fact that simulation is based on a very different approach than that from which the semi-empirical relation was obtained, our results are satisfactory as indicated by the usefulness of our method for simulating the rupture process on a fault plane. 


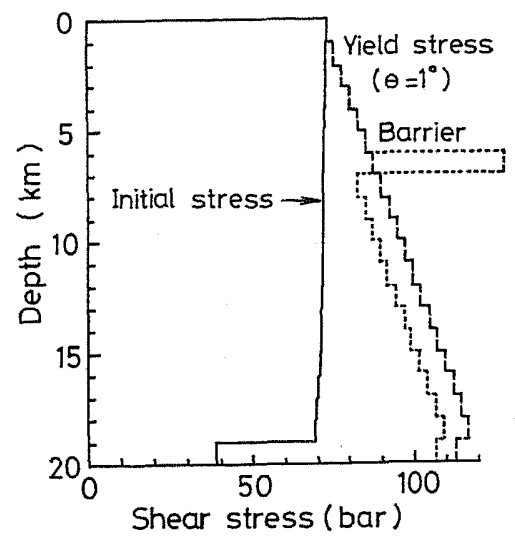

Fig. 18. Initial shear stress distributions in Cases 5 and 6.

\section{Simulation of a Barrier Model}

\subsection{Barrier model}

In our analyses, parameters such as stiffness, yielding stress and dynamic stress drop were assumed to be uniform in their respective layers and eventually a rupture would be transmitted successively along the fault. In an actual fault, however, there is a non-uniform distribution of strength along the fault plane. When the rupture front meets a barrier for which the yielding stress is higher than stresses within the vicinity, fracturing on the fault can be classified in three categories according to the strength of the barrier (DAS and AKI, 1977): 1) Rupture stops if the strength of the barrier is high enough; 2) The barrier is overcome and the rupture proceeds if the barrier strength is lower; and 3) At intermediate barrier strength, the rupture jumps the barrier and proceeds further. With intermediate barriers, the barrier will be fractured later or, under certain conditions, it will be left un-fractured.

In the following analysis, a single homogeneous layer in which a thrust-type fault was contained, was considered. Constants for the layer were assumed to be same as for the second layer of the preceding model shown in Fig. 5. The dip angle of the fault was $45^{\circ}$. Case 5 is a non-barrier model, the strength parameters of the fault being the same throughout the fault, cohesion being 70 bars and the friction angle $1^{\circ}$. Case 6 has a barrier element at the depth of $6 \mathrm{~km}$. Cohesion was assumed to be 110 bars for this element, 70 bars for a joint element shallower than the barrier and 62 bars for deeper regions. A common friction angle of $1^{\circ}$ was assumed on the fault plane, and 20 bars was assigned as the stress drop for all the joint elements, regardless of the yielding stress.

The initial shear stress distribution (Fig. 18) is designated by a solid line. The broken line represents the yield shear stress determined from the MohrCoulomb's failure law in terms of cohesion and friction angle. The dotted line shows the yielding stress of the barrier in Case 6 . 


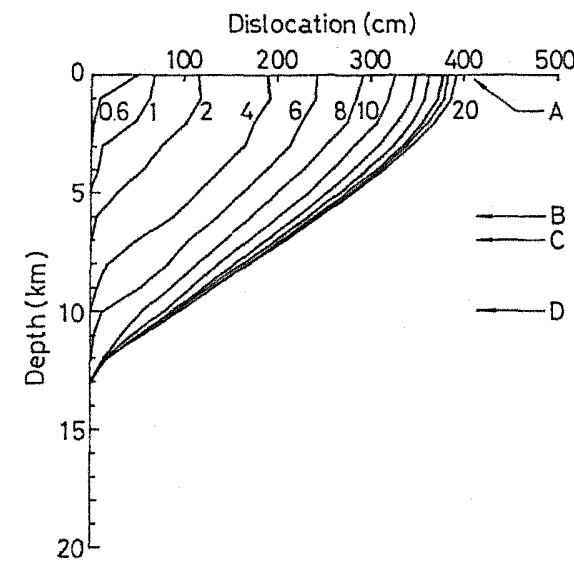

(a)

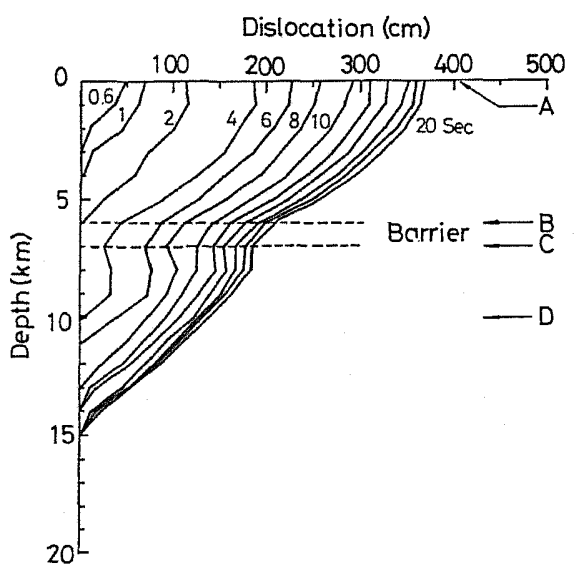

(b)

Fig. 19. Development of the dynamic fault rupture. (a) Case 5, (b) Case 6.

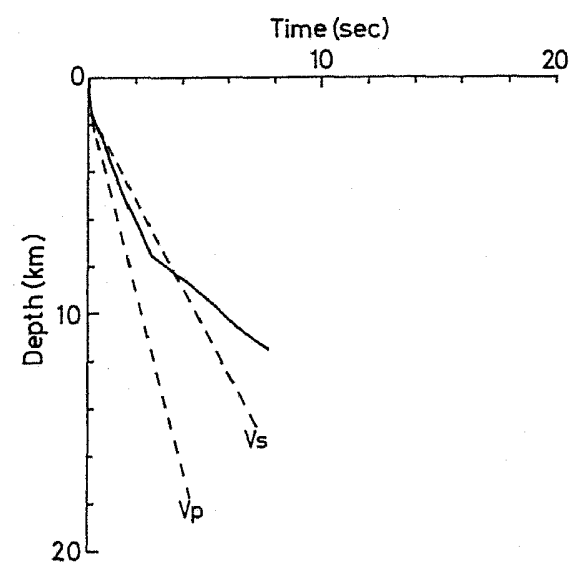

(a)

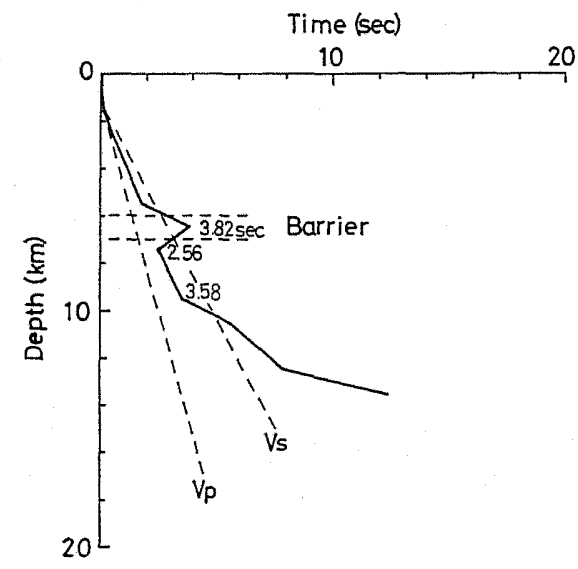

(b)

Fig. 20. Trace of wave front of simulation (solid line) and $\mathrm{P}$ and $\mathrm{S}$ waves (dashed lines). (a) Case 5, (b) Case 6.

\subsection{Transmission of rupture}

Figure 19 compares the difference in the distribution and development of dislocation for Cases 5 and 6 . As the yielding stress is smallest at the ground surface, rupture is initiated at the surface in both cases and gradually spreads into deeper regions; $13 \mathrm{~km}$ in Case 5 and $15 \mathrm{~km}$ in Case 6 which has the barrier. In our analysis, computations were terminated at $20 \mathrm{~s}$, but rupture continued beyond that time. Although the rupture was transmitted successively in Case 5, which has no barrier, it was momentarily stopped at the barrier in Case 6 . In the latter 
(a)
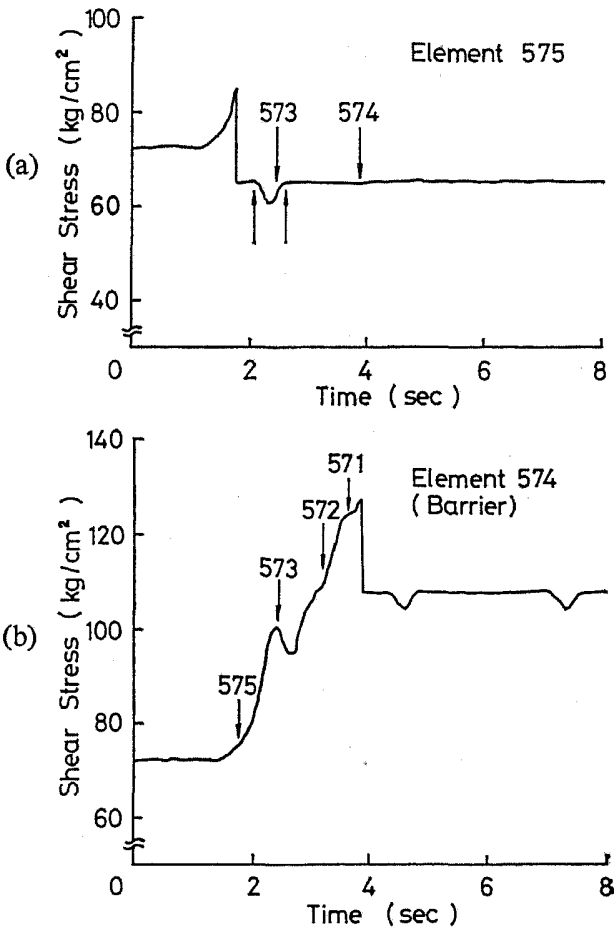

(a)

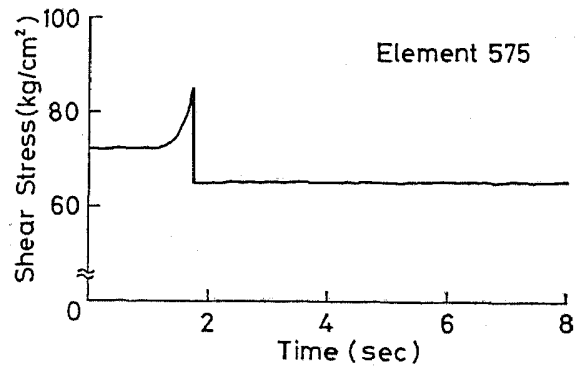

(b)

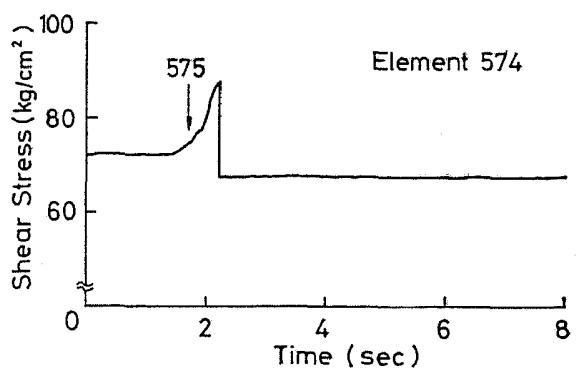

(c)

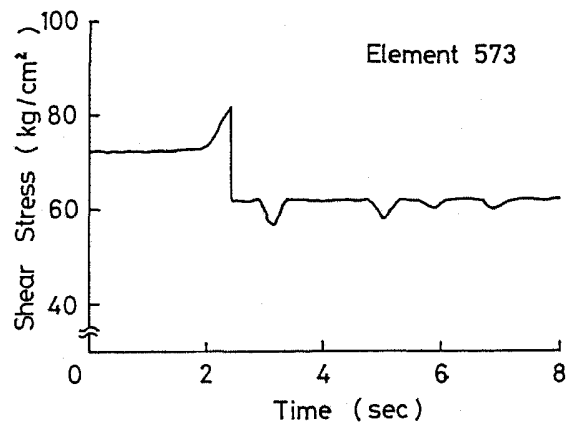

Fig. 21

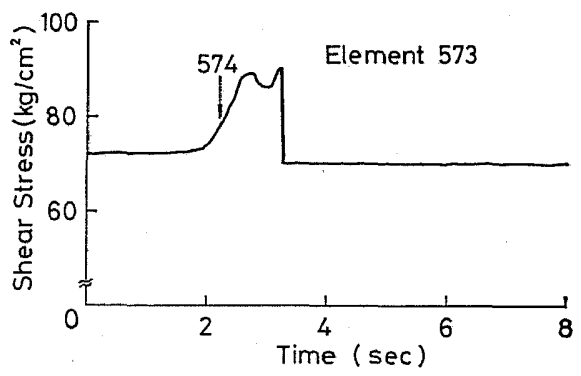

Fig. 22

Fig. 21. Time history of the shear stress in Case 6. (a) Element 575, (b) Element 574 (barrier), (c) Element 573.

Fig. 22. Time history of the shear stress in Case 5. (a) Element 575, (b) Element 574, (C) Element 573

case as shown in Fig. 20(b), after a few seconds' pause, the rupture jumped the barrier, and the next element was fractured. Because the rupture was stopped at the barrier, dislocation in the vicinity of the barrier (Fig. 19(b)) is less than that in Case 5 which has a smoother distribution of dislocation (Fig. 19(a)).

Transmission of the wave front with time is shown in Fig. 20(a) for Case 5 
Table 3. Comparison of values obtained from formula and F.E.M.

\begin{tabular}{|c|c|c|c|c|c|c|c|}
\hline \multirow{2}{*}{ Case } & \multirow{2}{*}{$\begin{array}{c}\text { Global } \\
\text { stress } \\
\text { drop } \\
\widetilde{\Delta \tau} \text { (bar) }\end{array}$} & \multicolumn{2}{|c|}{ Dislocation (m) } & \multicolumn{2}{|c|}{$\begin{array}{l}\text { Seismic moment } \\
\left(10^{26} \mathrm{dyn} \cdot \mathrm{cm}\right)\end{array}$} & \multicolumn{2}{|c|}{ Magnitude $M_{\mathrm{S}}$} \\
\hline & & Formula & F.E.M. & Formula & F.E.M. & Formula & F.E.M. \\
\hline 5 & 14.4 & 2.15 & 2.17 & 1.96 & 1.98 & 7.19 & 7.19 \\
\hline 6 & 13.0 & 2.24 & 1.99 & 2.72 & 2.42 & 7.28 & 7.25 \\
\hline
\end{tabular}

and for Case 6(b). Broken lines represent the fronts of $\mathrm{P}$ and $\mathrm{S}$ waves. In Case 5 , which has no barrier, the rupture developed with a velocity close to that of an $S$ wave for the first $2.4 \mathrm{~s}$, after which its velocity decreased. In Case 6 , with the barrier, after rupture had reached the barrier at $1.80 \mathrm{~s}$, the element beneath the barrier fractured before the barrier ruptured at $3.82 \mathrm{~s}$.

The time history of shear stress at three joint elements, including the barrier element in Case 6, are shown in Fig. 21; (b) the barrier element and (a) and (c) its upper and lower elements. The arrow $\downarrow$ indicates the time of rupture of the numbered joint elements, rupture developing in the sequence (a), (c), (b). At element 574, the barrier element, the shear stress increased sharply at the instant element 575 ruptured, and it was transmitted to element 573 shortly afterwards. Consequently, the rupture at element 573 , whose yield strength is less than that of barrier element 574, precedes the rupture of element 574. Shear stress at barrier element 574 again is increased by the rupture of element 573 , and eventually the barrier element is fractured.

The yielding stresses of elements 575,574 , and 573 in Case 5 are shown for comparison in Figs. 22 (a), (b), and (c). Rupture develops smoothly in the sequence of (a), (b), (c) as seen from the figure. A comparison of Figs. 21(a) and 22(a) shows that the development of the increase in shear stress of element 575 is exactly the same before the start of rupture in both figures. In the case shown in Fig. 21(a), shear stress decreased below the residual stress for a time; that is, sliding stopped during this period which is designated by the two upward arrows. This cessation of sliding is due to the existence of the barrier, element 574. After element 573 had fractured, element 575 again began to slide. These situations indicate the flow of stress to the barrier element from neighboring elements due to the re-distribution of stress. As shown here, this method describes the process of the re-distribution of stress and stress flow along the fault plane in the barrier model.

Fault parameters obtained by simulation and from the dislocation theory are given in Table 3. Simulation by the finite element method for Cases 5 and 6 were in good agreement, again. Figures 23 and 24 show the histories of dislocation with time for Cases 5 and 6 . A to $\mathrm{D}$ representing the locations indicated in Figs. 20 (a) and (b). Arrows in Fig. 24 indicate the rupture time of the barrier. A comparison of these curves shows that the effect of the barrier on the sourcetime function is not as significant as it is on the rupture process. But, as shown 

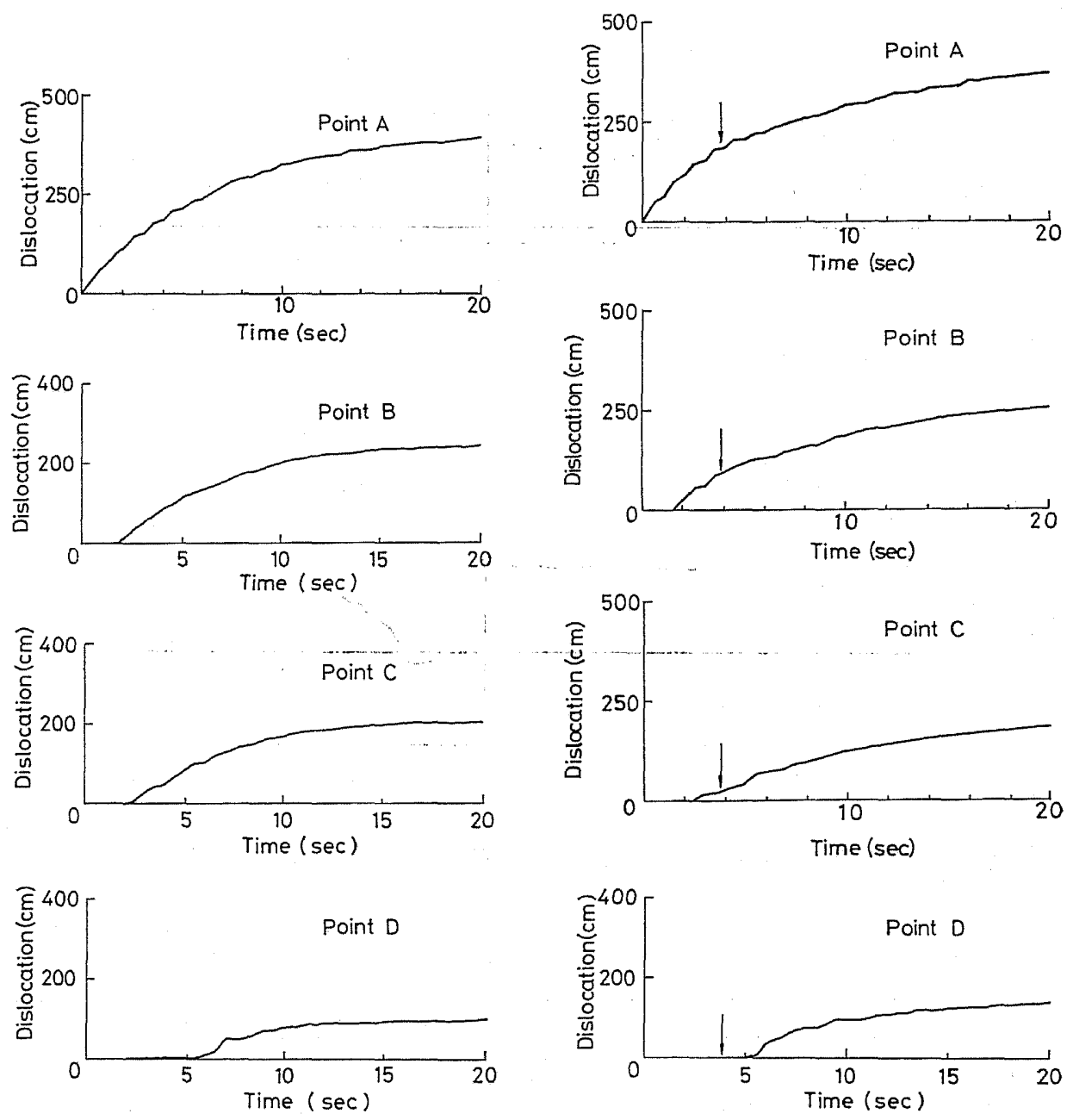

Fig. 23

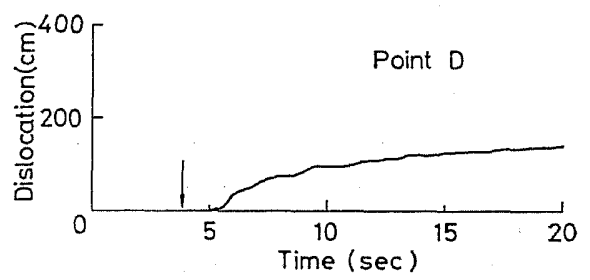

Fig. 24

Fig. 23. Source-time function in Case 5.

Fig. 24. Source-time function in Case 6.

in Fig. 24, the source-time function differs in shape at different locations on the fault plane.

Figures 25 and 26 show deformation curves at a site $8 \mathrm{~km}$ from the fault at ground surface; displacement, velocity and acceleration are shown from top to bottom. Figure 25 is the smooth model and Fig. 26 the barrier model. P and $\mathrm{S}$ waves generated from the barrier arrive at this observation point 1.32 and $2.49 \mathrm{~s}$ after rupture of the barrier. A comparison of time traces of the barrier and smooth models, for the horizontal and vertical components, shows that the acceleration amplitude of the barrier model becomes lower after about $5 \mathrm{~s}$ but becomes greater 

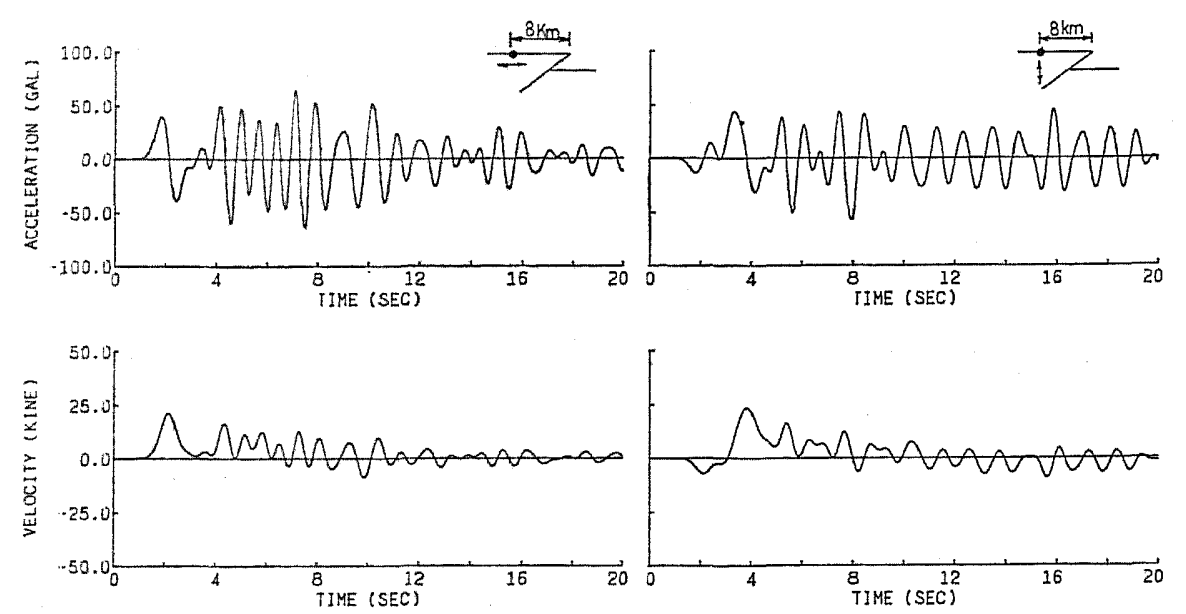

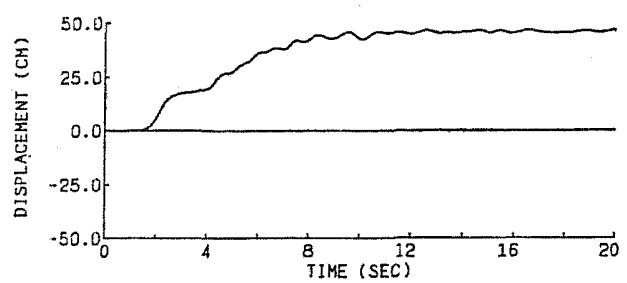

(a)

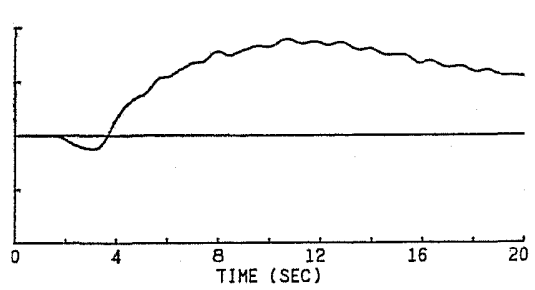

(b)

Fig. 25. Deformation curves for the upper block in Case 5. (a) Horizontal comp, (b) vertical comp.

again after about $6 \mathrm{~s}$ in comparison to those of the smooth model. Adding the 2.49-s traveling time of the $S$ wave from the barrier to the 3.82-s rupture time of the barrier gives $6.31 \mathrm{~s}$, where time is denoted by $\mathrm{S} 2$ in Fig. 26. $\mathrm{P}_{0}$ and $\mathrm{S}_{1}$ correspond to the arrival times of the $P$ and $S$ waves generated by the rupture of the element beneath the barrier. From these figures we see that the acceleration time curve is affected by the existence of the barrier; this also is valid for the displacement curve of the vertical component.

Parts (a) and (b) of Fig. 27 compare the attenuation characteristics of Cases 5 and 6, for the horizontal and vertical components. As with Fig. 16, the amplitude of the upper block is greater than that of the lower block, but the effect of the barrier is not significant.

As discussed above, our proposed method can be used to represent the flow and redistribution of stress on and around the fault plane, and the various phases of the seismic records are constructed as contributions from the barriers. In simulation the frequency component is limited, however, to a low range of less than $1.5 \mathrm{~Hz}$. A finer finite element mesh is necessary if we are to discuss deformation that includes higher frequency components, but it is difficult to obtain these conditions because of the capacity of the computer. 

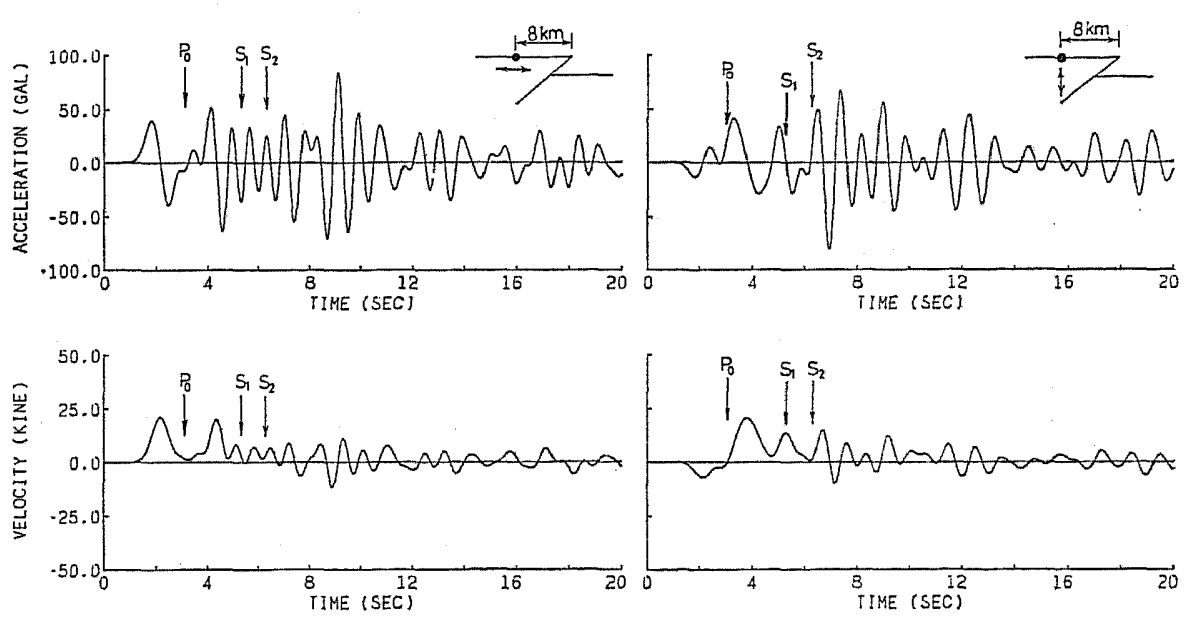

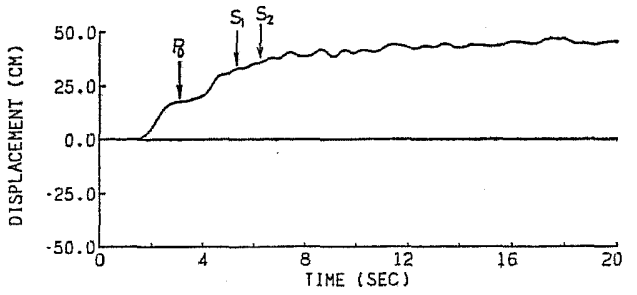

(a)

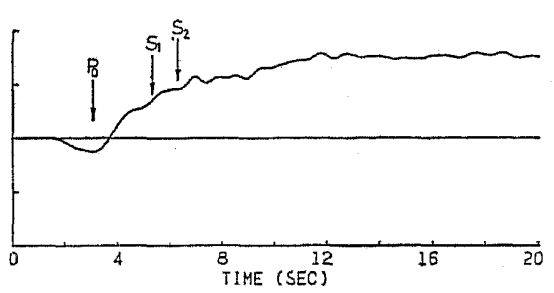

(b)

Fig. 26. Deformation curves for the upper block in Case 6. (a) Horizontal comp, (b) vertical comp.

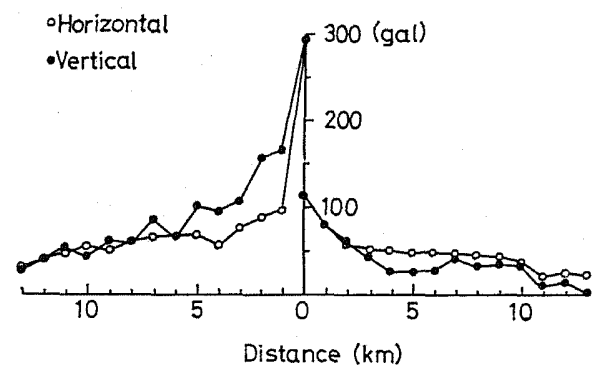

(a)

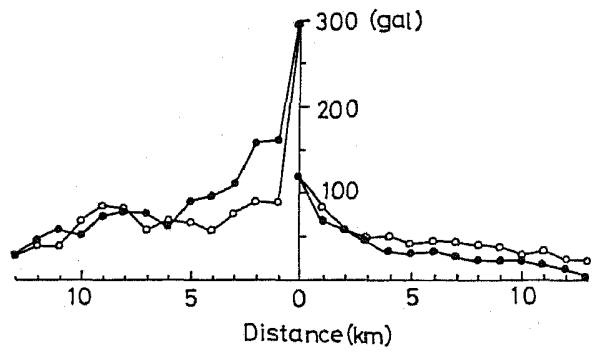

(b)

Fig. 27. Attenuation of peak acceleration. (a) Case 5, (b) Case 6.

\section{Conclusions}

This study has dealt with simulation of the fault rupture mechanism using a two-dimensional finite element method which introduced a joint element to represent the fault plane. In the dislocation theory, which is based on elastic wave transmission in a half space, such parameters as the magnitude of dislocation, 
ramp function, rupture velocity and stress drop are specified in advance of any analysis, even though these parameters are the results of rupture on the fault plane. Therefore, we adopted two parameters related to the strength of the fault plane, which are the yielding stress and stress drop. This first trial using our method has been limited to two-dimensional analysis. Interesting results, however, were obtained. These can be summarized as follows;

1) The magnitude of dislocation depends on both the stress drop and on the yielding stress and is proportional to the yielding stress if the ratio of stress drop to the yielding stress is the same.

2) The average value of dislocation obtained by our method compares well with the theoretical relation used to predict the magnitude of dislocation, which indicates the validity of our method for simulating the fault rupture process.

3) A thrust-type fault was treated in our analysis, and the general features of deformation at ground surface caused by actual earthquakes also were observed along with the simulation results.

4) We ascertained that this method is particularly useful for simulating the barrier model because the flow of stress in the vicinity of the fault plane is easily traced as is the process of redistribution of the stress field.

5) The direction of the transmission of rupture depends greatly on the initial stress distribution which also governs the starting point of the rupture.

In addition, problems to be analyzed in the next step were made clear:

1) Three dimensional analysis must be used to investigate the details of the fault rupture mechanism.

2) A finer mesh is needed for analyses that include a higher frequency component, especially for simulation of the acceleration curve.

3) Many more simulations are necessary for investigations of the general features of the fault-rupture process using models with different dip angles and different barrier distributions.

We sincerely thank Mr. Hideaki Kishimoto of Japan Computer Consultants, Osaka and Mr. Takashi Yoshimura, former graduate student of Kyoto University, for their help with our computations and we gratefully acknowledge critical reviews and useful discussions by Prof. Ryosuke Sato. This research was supported by a Grant-in-Aid for Research in Natural Disasters, the Ministry of Education, Science and Culture of Japan.

\section{REFERENCES}

ARChuleta, R. J. and G. A. Frazier, Three-dimensional numerical simulations of dynamic faulting in a half-space, BSSA, 68, 541-572, 1978.

DAS, S. and K. AKI, Fault plane with barriers; A vertical earthquake model, J. Geophys. Res., 82, 5648-5670, 1977.

GeLLER, R., Scaling relation for earthquakes source parameters and magnitude, BSSA, 66, 1501-1523, 1976.

Goodman, R. E., Methods of Geological Engineering in Discontinuous Rocks, West Publishing Company, 472 pp., 1976.

Jungles, P. H. and G. A. Frazier, Finite element analysis of the residual displacements for an 
earthquake rupture. Source parameters for the San Fernando earthquake, J. Geophys. Res., 78, 5062-5083, 1973.

KanamoRi, H., Physics of earthquake, in The Earth Science, ed. H. Kanamori, No. 8, pp. 108116, Iwanami, Tokyo, 1978 (in Japanese).

KanAmori, H. and D. L. Anderson, Theoretical basis of some empirical relations in seismology, $B S S A, 65,1073-1095,1975$.

Kostrov, B. V., Self-similar problems propagation of shear cracks, J. Appl. Math., 28, 10771087, 1964.

KuHLemeyer, L. and J. Lysmer, Finite element method accuracy for wave propagation problems, ASCE, J. EM, 421-427, 1973.

LYSMER, J. and L. KUHLEMEYER, Finite dynamic model for infinite medium, ASCE, EM4, 859$877,1969$.

McCown, D. W., P. Glover, and S. S. Alexander, A static and dynamic finite element analysis of the 1971 San Fernando, California, earthquake, Geophys. J. R. Astron. Soc., 48, 163-185, 1977.

Melosh, H. J. and A. RaEfSKy, A simple and efficient method for introducing faults into finite element computations, BSSA, 71, 1391-1400, 1981.

Mrkumo, T. and T. MrYATAKe, Dynamical rupture process on a three-dimensional fault with nonuniform frictions and near-field seismic waves, Geophys. J. R. Soc., 54, 417-438, 1978.

MrYATAKE, T., Numerical simulation of earthquake source process by a three dimensional crack model. Part I. Rupture process, J. Phys. Earth, 28, 565-598, 1980 a.

MrYATAKE, T., Numerical simulations of earthquake source process by a three-dimensional crack model. Part II. Seismic waves and spectrum, J. Phys. Earth, 28, 599-616, 1980 b.

NEwMARK, N. M., A method of computation for structural dynamics, Proc. ASCE, 85, EM3, 67-94, 1959.

ODA, H. and T. HrRasawA, The effect of medium heterogeneity upon the static deformation due to a longitudinal shear crack, Sci. Rep. Tohoku Univ. Ser. 5, Geophys., 23, 115-132, 1976.

SATO, R., Theoretical basis on relationships between focal parameters and earthquake magnitude, J. Phys. Earth, 27, 353-372, 1979.

TokI, K. and F. Mrura, Non-linear seismic response of soil-structure interaction system, Earthq. Eng. Struct. Dyn., 11, 77-89, 1983.

Toki, K., F. Mrura, and Y. OGuni, Seismic stability of slope subjected to strong ground shaking, Earthq. Eng. Struct. Dyn., 13, 151-171, 1985.

Toki, K., F. MiURA, and T. Yoshimura, Simulation of spontaneous rupture propagation and strong earthquake motion by the nonlinear finite element method, Annu. Disas. Prev. Res. Inst., Kyoto Univ., 26 B-2, 15-34, 1983 (in Japanese).

ToKI, K., T. SATo, and F. Mrura, Separation and sliding between soil and structure during strong ground motion, Earthq. Eng. Struct. Dyn., 9, 263-277, 1981.

Yoshikawa, S., Y. IWASAKI, and M. TAI, On the damage caused by the 1980 Algeria earthquake, 16th Annual Conv. of the Japan Society for Soils and Foundation Engineering, pp. 33-36, 1981 (in Japanese). 